\section{Stanford Narcolepsy Questionnaire}

Helga Peter

Marburg, Deutschland

\section{Synonyme}

Stanford Narkolepsiefragebogen

\section{Definition}

Validierter Fragebogen mit 146 Fragen zu narkolepsietypischen Symptomen. Insbesondere hilft er $>$ „Kataplexie“ von anderen Formen der „Muskelschwäche“ zu differenzieren. Nachteil des Fragebogens ist die fehlende Einteilung in Schweregrade der einzelnen Symptome.

Siehe auch $\triangleright$,Narkolepsie“. 